\title{
Simulation, Role-play and Training in Interpretation Teaching
}

\author{
Chunyi LI \\ International Education Department \\ Hainan College of Economics and Business \\ Haikou, China \\ e-mail: 68272995@qq.com
}

\begin{abstract}
This paper focuses on the importance of simulation and role-play as well as the major skill trainings methods in interpretation teaching. The focus is on theory, with a class experiment. First, the development of interpretation, general features of interpretation and two common criteria of interpretation are explored as they are closely relate to the interpretation teaching. It is then suggested that simulation and role-play, which play essential roles in arousing students' interests and improving their knowledge, should be applied in interpretation teaching. The training methods, which should pay more attention to skill trainings, are also considered in this paper.
\end{abstract}

Keywords-interpretation teaching; simulation and role-play; skill trainings

\section{INTRODUCTION}

With the development of Chinese modern society, China is becoming more and more positive in the world. China has joined the Worth Trade Organization several years ago and has gained the right to hold the 2008 Olympic Games. All these achievements lead to a greater demand of interpreters who play significant roles in Chinese communication with the world. Interpretation is becoming a compulsory course for English majors in higher education in China. Therefore, improving the quality of interpretation teaching as well as students' interpretation skills and cultivating more and more qualified interpreters are considered to be tough and urgent tasks.

This paper focuses on the importance of simulation and role-play as well as the major skill trainings methods in interpretation teaching. The training methods, which should pay more attention to skill trainings, are also considered in this paper.

The term interpreting is defined in Concise Oxford Dictionary (Pearsall 1999) as "explain the meaning of; perform a creative work in a way that conveys one's understanding of the creator's ideas." Practice proves that interpretation cannot only be considered as a linguistic undertaking, but it is also viewed as a kind of communication. Interpretation requires not only linguistic knowledge, but also encyclopedic knowledge during the complicated discourses or speeches. While most of the scholars emphasize that translation and interpretation basically function the same, some, especially these interpreters hold the idea that the two are not the same, they even believe that they cannot be compared with. In the practice of actual translation and interpreting, "some differences are not controversial" (Baker 41). Scholars are convinced that the most apparent ones of these differences are that translators are responsible for written language and they are given sufficient time to refine their work. While interpreters need to deal with oral language and they lack time to do a better job.

Interpretation is a form of oral expression. By changing one kind of language to another one accurately and quickly when one hear or read the message. Interpretation is thought to be an act of communication aimed at expressing and exchanging message. It is one of the basic language tool deeply relied on by human beings in the exchange of crossculture and cross-nation.

The activity of interpretation by human beings is not that kind of activity that mechanically changes the marks of information of source language into target language marks. However, it is a positive and creative activity of interpretation that aims at exchanging information. Therefore, interpretation is not a single language activity only taking semantic content of a sentence as the unite of interpretation, but a comprehensive language activity which attaches equal importance to the content of communication including the meanings of words, contents, language style and the meanings of culture and nation. From these statements mentioned above, we can conclude that interpretation is not only a language activity but also an activity of culture, psychology and society.

\section{INTERPRETATION TEACHING}

Interpretation teaching did not draw much attention from people for a long time. There are still many schools that haven't set up classes of interpretation. With China's joining WTO and the development of international cooperation, China is urged to produce more and more interpreters. Nowadays, more and more people are attracted to take part in the exam of interpretation certificate of all places in China. Objectively speaking, these phenomena can be considered as recognitions for Chinese interpretation teaching. However, interpretation is still a new thing in China and teaching methods are just taking off. After decades of exploration and practice, people are gradually aware that interpretation teaching is different from language teaching in teaching goals, teaching principles or teaching tools and methods. This is determined by the rules of interpretation. 


\section{A. Spoken English Teaching and Interpretation Teaching}

Spoken English is the language used in talks, and it is different from written English. It is a basic communication competency of language. Other competencies include listening competency, reading competency, and writing competency. Oral English teaching is a kind of competency training and it belongs to language teaching. Materials of daily life are the major content for oral English teaching, for example, introduction, greeting, invitation, notice, request, suggestion, etc. The aim of oral English teaching is to improve students' English proficiency that is one part of English proficiency. Students are required to express their own thoughts and feelings clearly by English they have mastered. We can see that the aim of oral English teaching is not limited to the competency of oral expression, but the content of expression of students' own thoughts. Students not only practice their oral English but their debate competency as well in oral English teaching.

Interpretation is a much more super skill of profession. Interpretation requires skill trainings. The content of interpretation teaching focus on special themes or professions, for example, industry, agriculture, economics, technology, revolution, foreign trade, medicine, education, sports, environment, religion, family, population, women, children and so on. Interpretation teaching is different from language teaching either in teaching goals, principles or tools and methods. Course establishment of interpretation should pay more attention to skill training.

\section{B. Simulation and Role-play in Interpretation Teaching}

Traditional teaching methods are influenced greatly by educational viewpoint of behaviorism in the 1950s and teacher is the major role in class and controls the whole class. As a result, knowledge is transmitted in single direction only from teacher to students. Obviously, this kind of old teaching model cannot reach the goal of cultivating communication competency in interpretation teaching. From the 1980s, the main point of teaching has changed to cultivate students' learning and thinking competency. Students are encouraged to take part in class teaching and teachers become supervisors for them.

During teaching, teachers attach more importance to students' participation in class and they spend more time on simulation and role-play in class. Some basic interpretation theories are necessary but most of the time is left for students to practice.

Students are given more time to find out the problems of study and manage to handle them. They learn quite a lot from practice. By simulation and role-play, students are thought to experience all the processes of interpretation. Simulation and role-play will help cultivate their psychological quality.

Interpretation teaching requires more practice. Teachers should pay more attention to teaching methods and apply more significant models of activities to arouse students' interest in study.

\section{1) Class experiment}

The creation of atmosphere on the spot can lay a foundation for students' psychology. Simulating the speaking and interpretation on the spot reflect the principles of extemporaneousness and abruptness. The purpose of it is to help student experience the trouble brought about by changes and take measures to handle them under real interpretation environment.

Teachers can choose some materials about the great events happened recently in the world as the major topics for the students to simulate in class because most students are interested in the new events and are familiar to them. Traditionally, students are taught new words and phrases by reading or reviewing them in class with their teacher. However, simulation and role-play can be a good way of both improving students' knowledge and arousing their interest in class. By simulating in class, we can gain a better result of interpretation teaching compare to that of traditional one.

The press conference held by the third session of the 12th National People' Congress on the morning of March 15, 2015 was well known by the students. And most students are very concerned about the answers given by our Premier Li Keqiang to the questions given by Chinese and foreign journalists. We took advantage of the conference and simulated one in class. Our teacher needed to prepare the materials that go with the record of the press conference prior to the class. Played the record to students first at the beginning of class and made them feel that they were just on the spot. Then separated students into several groups of which consist of a so-called premier, an interpreter and four journalists from both home and abroad. Both the "premier" and the "interpreter" sit in the platform and the "journalists" sit in the students' seats. The "premier" was asked questions given by the "journalist" and the "interpreter" was responsible for the interpretation. Then students took turns to change their roles. By creating a real environment of press conference, students made progress in improving their ability of handling problems while interpreting.

\section{a) Meeting simulation}

According to the teacher's syllabus, two students are set to the spoken men's chairs and interpreters' chairs as spoken men and interpreters. The teacher sits in the audience chair. Before class, teacher can provides some simple materials and prepare the spot. If these materials are familiar to students, it is much better. Therefore, most of the students can interpret before the so-called audience and express the goal of the activities and forms and content of the activities. Students can focus on the good habits owned by public speaker because the pressure of language is reduced. Take one simulation of news conference for example; all students and teachers give suggestions to the grace of the interpreters, including their behavior, expression, tag, and clothes. From these experiments, after several times of simulation, students can get rid of their bad habits like unnatural expression, embarrassment, and timidness of looking at audience. Some students have changed their bad habits by all means after class with the help of friends.

\section{b) Business negotiation simulation}

Conversational interpretation is a complex form used broadly in negotiation communication, business and foreign 
activities. For example, we can simulate negotiation under such a condition, after goods are shipped to the port, buyers found that goods are destroyed greatly or they are not consistent with the items on the contract and ask for compensation from sellers. Separate students into two groups, each with three members of which one stands for buyer, one for seller and the other one for interpreter. According to the requirement of interpretation teaching, interpreters are asked to interpret some simple sentences and master some usual practice about compensation and then change to interpretation of paragraphs as a unit. That is to say, both parts of buyers and sellers try to protect their own benefit. Students think that simulation of business negotiation will help enhance their adaptability for their future work.

2) Result comparison

By simulating, students pay more attention in the process of study than the results. It can help them to study positively and forwardly. The design of class syllabus provides enough sense of security for student in class, and gives them more courage to take the challenge of new knowledge. Most of the students have very strong sense of self-protection. They are reluctant to reveal their shortage in knowledge or mistake in study. By simulating, they can take part in class activities positively. Simulation requires cooperation among students, and helps them realize their value. They have a sense of belonging. The sense of belonging is a powerful motivation. If students are considered to be a significant one, they are more willing to study and take part in activities. By cooperation, for example, group work can help students realize their value.

\section{Skill Trainings in Interpretation Teaching}

"Prerequisites for interpretation are basically four-fold: (1) a strong sense of duty; (2) linguistic proficiency; (3) encyclopedic knowledge; (4) mastery of interpretation techniques" (Zhong 4). These fundamental requirements seem to be simple, but it is very hard to meet. Those who have excellent language and have mastered a wild range and scope of general knowledge are considered to be good interpreters, however, as a matter of fact; a number of those people are not competent to be interpreters. Interpreters have to undertake an arduous process of training. A great amount of practice is necessary for interpreters to acquire the basic techniques and to overcome difficult situations.

Because of the features of interpretation, it is a key point to apply interpretation skills in interpretation teaching. It is better to use both single and comprehensive methods for interpretation skill trainings. It is more important for students to master some interpretation skills, which include several aspects as follows.

1) Comprehension and short-term memory training

According to Li Xuebing, the processes of interpretation are:

The first step: $\mathrm{I}=\mathrm{L}+\mathrm{N}+\mathrm{M}+\mathrm{C}$

The second step: $\mathrm{I}=\mathrm{Rem}+\mathrm{Read}+\mathrm{P}$

$\mathrm{I}=$ Interpreting

$\mathrm{L}=$ Listening and Analyzing

$\mathrm{N}=$ Note-taking
$\mathrm{M}=$ Short-term Memory Operations

$\mathrm{C}=$ Coordination

$\mathrm{R}=$ Remembering

Read $=$ Note-reading

$\mathrm{P}=$ Production

From the formulations mentioned above, we can see that the first step as well as the most important one is the comprehension of source language. If we cannot comprehend it, we cannot interpret it correctly. Short-term memory is an essential part for interpretation. A good method of memory can be a helpful one for interpreters to finish their tasks. According to the psychologists, short-term memory can only last for twenty seconds to thirty seconds. However, interpreters have to interpret contents ranging from several seconds to several minutes. Therefore, comprehension will help short-term memory. Remembering what the speaker said can help understand better. Therefore, in order to facilitate the interpretation process, it is preferable to give notes-taking training. Usually, there are several kinds of marks and abbreviations familiar to us.

\section{a) Mathematics marks}

Most of the time, mathematics marks play important roles in interpretation.

- > means "exceeds, more than, superior to".

- < means "less than, inferior to".

- =means "the same as, equal to, similar to".

- $\quad \neq$ means "difference, disparity".

- [] means "among, within".

- + means "plus, add, moreover, besides".

- - means "minus, deduct, except".

b) Punctuations

Punctuations also express certain meanings.

- $\quad$ : questions, doubt;

- $\quad$ : : I think, I hope;

- ...: not really enthusiastic;

- - : extremely crowded.

While training, we can follow methods as follows. Collect and print some common abbreviation marks for students as well as some examples on the note of interpreters. Ask students to recite the contents of source language firstly and tell the main points of it. Secondly recite the contents again with target language. Finally, separate the whole passage to several parts and take exercises. We can also ask students to come to the blackboard to take exercises and comment on their job. After this kind of training, students will form their own habits of memory. Some students remember the contents by bilingual or just remember the key words.

2) Knowledge accumulation training

A professional interpreter should have a good command of knowledge to cope with various subjects in different situations. Therefore, knowledge accumulation is an essential process for their skill trainings. Two major ones are worth mentioning in this article.

\section{a) Interpreting quotations training}

China is a country with a long history and abundant philosophers. The words and sentences they spoken were 
recorded by the generations followed them. Quotations are those famous sentences remembered from generation to generation. As we all know, chief officials from countries all over the world intend to quote these famous sentences when they are giving lectures to express their emotion and viewpoints and to eulogize their culture and traditions. For example, our former Premier Wen Jiabao once quoted sentences said by Meng $\mathrm{Zi}$ who was a famous philosopher of China in a news conference to encourage people in our country to think about the potential danger when we are in peace. One prospers in worries and hardships and perishes in ease and comfort. Quotation is a tough task for interpreters to deal with. Therefore, interpreters should master a number of these quotations that is also a part of interpretation teaching. Teachers and students can collect them together and share them in class.

\section{b) Interpreting proverbs training}

People commonly use proverbs, which express deep meanings by simple words. Accurate interpretations of proverbs are tough for interpreters to deal with. Therefore, remembering an amount of proverbs is very necessary for interpreters. We just mention some proverbs in this paper.

Facts speak louder than words.

Well begun is half done.

Much will have more.

Have a card up one's sleeve.

The pupil outdoes the master.

There is no smoke without fire.

Man proposes, God disposes.

3) Comprehensive training

We need to give a comprehensive training on the basis of the single training mentioned above, that is to practice those skill trainings in an imitated situation. For example, when we are teaching the chapter about education, we first ask students to get familiar with the phrases and expressions about education, and then, prepare some materials related to education and school to make use of the knowledge students have already mastered before class. Organize students to hold a imitated news conference and appoint two students as the leaders of the school, several ones as interpreters, and the rest of students can ask questions as if they are parents, student representatives, and teacher representatives. In this case, students can receive a comprehensive training by applying the knowledge they have accumulated and the skills they have mastered. The more practice they get, the more skilful they will become.

\section{CONCLUSION}

To make a conclusion, English is becoming more and more popular in China, and interpretation is now a compulsory course for English major in higher education. Interpretation is a very special course that demands lots of practice for its skills. The method of training, the time the training takes and the books used to teach are different according to different people. During the process of training, we need some theories to be our guide. Simulation and roleplay play important roles in interpretation teaching. They are very helpful for interpretation teaching. At the same time, we need to pay more attention to skill trainings and improve students' comprehensive competency of English.

\section{ACKNOWLEDGMENT}

In this paper, the research was sponsored by Hainan Social Science Association Project (No. HNSK (zc) 16-45).

\section{REFERENCES}

[1] Baker, Mona, ed. Routledge Encyclopedia of Translation Studies. London \& New York: Routledge, 2001.

[2] Pearsall, Judy, ed. Concise Oxford Dictionary. New York: Oxford UP, 1999.

[3] Riccardi, Alessandra, ed. Translation Studies: Perspectives on Emerging Discipline. London: Cambridge UP, 2002.

[4] Xuebing Li. Objectives and Content for English Interpretation Teaching. Journal of Beijing International Studies University. J. Beijing, 2005, (2).

[5] Shukong Zhong. Practical Book for Interpretation.Beijing:China Translation Corporation, 1999. 